\section{Incidence of visual loss in the Ponza Eye Study, Italy}

C Nucci' ${ }^{1}$, C Cedrone ${ }^{1}$, F Culasso ${ }^{2}$, F Ricci ${ }^{1}$,

M Cesareo ${ }^{1}$, A Corsi $^{1}$ and L Cerulli

\begin{abstract}
Aim To study the incidence of visual loss over a 12-year period in the survivors of an original cohort aged 40 years or older at baseline. Methods Visual acuity (VA) was measured by means of a standardized logMAR chart. World Health Organization definition of blindness and low vision was adopted (respectively, best-corrected VA $>1.3 \log$ MAR or a visual field $<10^{\circ}$ around central fixation, and bestcorrected VA $>0.5-1.3 \log$ MAR or a visual field $<20^{\circ}$ around central fixation). Moreover, binocular visual loss incidence (VA > 0.5 $\log$ MAR) was calculated in a 'healthy' group who had uncorrected VA of $0.0 \log$ MAR or better in both eyes at baseline and absence of eye diseases.
\end{abstract}

Results Of the 584 eligible survivors, 411 $\mathbf{( 7 0 . 7 \% )}$ had a 12 -year follow-up visit. The overall incidence figures were as follows: bestcorrected binocular blindness $(0.7 \%)$, binocular low vision (3.9\%), monocular blindness $(2.7 \%)$, and monocular low vision $(5.0 \%)$, respectively. The results for presenting VAs were 1.2, 9.5, 4.2, and $15.3 \%$. Figures for uncorrected, best-corrected, and presenting binocular visual loss incidence in the 'healthy' group were respectively $12.7,0.9$, and $3.7 \%$. Conclusion The discrepancy between the ideal and real situations that emerges from this study has important implications for health-care planning. Over a period of 12 years, a substantial percentage of 'healthy' subjects will have to seek medical care. Incident visual loss was caused mainly by untreated cataract, glaucoma, myopia, and agerelated macular degeneration.

Eye (2005) 19, 175-182. doi:10.1038/sj.eye.6701444

Published online 25 June 2004

Keywords: blindness; low vision; incidence; population-study

Figures published by the World Health Organization (WHO) on the prevalence of blindness among adults in Europe range from $0.2 \%$ in France (1985) to $0.7 \%$ in the United Kingdom (1991). If we consider the subgroup aged greater than or equal to 40 years, we find the highest prevalence in Malta: $2.5 \%$ (1989). ${ }^{1}$ Studies conducted in Italy reveal an estimated prevalence of blindness of approximately 0.5 and $1 \%$ for low vision. ${ }^{2-6}$

Although prevalence rates are important, incidence rates for visual impairment reveal more about the natural history and current causes of these conditions, and this information is essential if effective corrective measures are to be adopted. Incidence figures for Italy have been furnished by the Priverno Eye Study, in which baseline participants were re-examined after 7 years. ${ }^{7}$ Similar data are available for the United States, ${ }^{8,9}$ Australia, ${ }^{10,11}$ and even a rural community in southwest Uganda, ${ }^{12}$ although the follow-ups vary widely from study to study.

Within the framework of a project sponsored by the Italian National Research Council, ophthalmological data collected during a population-based study conducted in the municipality of Ponza were analysed. ${ }^{5}$ Baseline figures for 1028 subjects (aged 40 years and over) examined in 1988 revealed an overall prevalence of visual impairment of $9.3 \%$, that is, binocular blindness or low vision in 1.3 and $2.2 \%$, respectively, and monocular impairments in 2.6\% (blindness) and 3.2\% (low-vision). The present report contains 12-year incidence figures for blindness and low vision in the survivors of the original Ponza study population.

\section{Methods}

Between 1986 and 1988, standardized ophthalmologic exams were performed on the residents of Ponza, Italy. The town includes the entire $7.3 \mathrm{~km}^{2}$ of the Island of Ponza, which is located 18 miles off the western coast of Italy. All official residents of the municipality (3292 persons, 1430 of whom were 40 years of age and over) were invited to participate in the
${ }^{1}$ Physiopathological Optics Department of

Biopathology and Diagnostic

Imaging, University of Rome Tor Vergata, Rome, Italy

${ }^{2}$ Medical Statistics Department of Experimental Medicine

University of Rome La

Sapienza

Rome, Italy

Correspondence: C Nucci Cattedra di Ottica

Fisiopatologica

Dipartimento di

Biopatologia e Diagnostica per Immagini, Università degli Studi di Roma 'Tor Vergata', Via Montpellier 1, 00133 Roma, Italy Tel/Fax: + 39062026232

E-mail: nucci@

med.uniroma2.it

Received: 17 September 2003

Accepted: 6 January 2004 Published online: 25 June 2004

Research supported in part by the contribution of the Italian MIUR - Ministry of Instruction, University and Research - 1998-2000, Project no. 9806216964 
ophthalmological study. Of 1226 eligible persons aged 40 years and over (546 male and 680 female subjects), 1028 (445 men, 583 women) completed the baseline ophthalmological examination. Gender-specific participation rates were $81.5 \%$ (males) and $85.7 \%$ (females). The 204 ineligible persons were subjects maintaining the legal residence in the municipality of Ponza but actually living outside at the time of the examinations.

A series of demographic, social, and clinical variables were assessed: age, marital status, years of education, occupation, smoking, alcohol intake, cardiovascular diseases, diabetes, hypertension, myopia, high intraocular pressure (HIOP), glaucoma, cataract, diabetic retinopathy, and age-related macular degeneration (AMD).

Examinations were performed in the outpatient clinics of the Local Health Unit. The standardized procedure used for all participants included automated refraction tests (administered by an orthoptist, who also recorded the patient history), keratometry, measurement of uncorrected, best-corrected, and presenting visual acuity (VA), slit-lamp examination of the anterior segment, applanation tonometry, mydriatic slit-lamp examination for lens opacities, and fundus examinations (using direct and indirect ophthalmoscopy). Central 30-2 fullthreshold tests were also administered with the Humphrey Field Analyzer ${ }^{13}$ to all patients suspected of having glaucoma (ie, those with previous diagnoses and/or family history of glaucoma, shallow anterior chamber detected during slit-lamp examination, intraocular pressure (IOP) $>20 \mathrm{mmHg}$, cup/disc ratio 0.5 or greater, OD vs OS difference in cup/disc ratio of 0.2 or more) or hereditary degenerative disease of the retina (based on previous diagnosis, family history, funduscopic findings); all those who reported subjective visual-field restriction; and 50\% (randomly selected) of those with none of the previously cited characteristics. Deficits that emerged were defined more completely based on retesting with a Custom Grid ( $2^{\circ}$ spacing).

VA was measured at a distance of $4 \mathrm{~m}$, as previously described, ${ }^{14}$ using a standard 10-letter logarithmic chart designed according to the basic recommendations of the National Academy of Sciences -National Research Council. ${ }^{15}$

Visual loss was classified according to WHO recommendations as follows:

Blindness - Best-corrected VA of $>1.3 \log$ MAR (equivalent of $<3 / 60$ or $<1 / 20$ or $<20 / 400$ ) or a visual field $<10^{\circ}$ around central fixation. (These criteria correspond to ICD-10 categories 3-5 of visual impairment.)

Low vision - Best-corrected VA of $>0.5-1.3 \log$ MAR (equivalent of $<6 / 18-3 / 60$ or $<3 / 10-1 / 20$ or $<20 / 70$ $20 / 400$ ) or a visual field $<20^{\circ}-10^{\circ}$ around central fixation. (These criteria correspond to ICD-10 categories 1-2 of visual impairment.)

Binocular impairment was defined based on findings in the better eye; monocular impairment was classified according to VA in the affected eye (VA in the fellow eye being normal or near-normal).

After 12 years of completion of the baseline examination of the population (March-June 2000), a follow-up examination was conducted on the surviving members of the original cohort (identified by means of municipality records). Eligibility criteria for enrolment in this phase of the study included age $>40$ years at the baseline examination and current residence and presence in Ponza at the time of the follow-up examinations. Subjects who satisfied the age and residence criteria received a letter inviting them to take part in the followup examinations, and the objectives and methods to be used were described. To improve community acceptance of the study, no attempt was made to exclude subjects who had presented visual impairments at the baseline examination. Those who did not reply to the invitation and those who declined (by means of a return form) were considered 'unexplained refusals', and no further attempt was made to identify the reason for the subject's decision. Those who accepted the invitation were contacted by phone to set up an appointment. Subjects who cancelled or missed their appointments were contacted by examiners to determine the reason for the cancellation.

The subjects who took part in the follow-up study were examined by the same ophthalmologist and the same orthoptist who had examined the baseline population, using the same methods and classification criteria. Humphrey Field Analysis and Custom Grid testing (see baseline study above) were limited to patients with suspected glaucoma or hereditary degenerative retinal disease. Informed written consent was obtained from all these participants.

Incidence of binocular blindness was defined as development of VA $>1.3 \log$ MAR (or a visual field $<10^{\circ}$ around central fixation) in the better eye in an individual who had best-corrected VA less than or equal to $1.3 \log$ MAR or less in one or both eyes at baseline. Incidence of binocular low vision was defined as development of VA $>0.5-1.3 \log$ MAR (or a visual field $<20^{\circ}$ around central fixation) in the better eye in an individual who had best-corrected VA less than or equal to $0.5 \log$ MAR in one or both eyes at baseline. Incidence of monocular blindness and monocular low vision was defined by VA in one eye only at follow-up in comparison with the VA in both eyes at the time of the baseline examinations. 
To identify possible discrepancies between the 'ideal' picture based on best-corrected VA and that which actually exists in the population, we also calculated the incidence rates for visual loss based on presenting $\mathrm{VA}$, that is, the acuity provided by the corrective lenses (if any) that were actually used by the patient for driving, work, and other activities of daily life.

Finally, we also calculated incidence rates in the subgroup of 110 subjects considered 'ophthalmologically healthy' in the original examination. At baseline, these subjects all had uncorrected baseline VAs equal or better than $0.0 \log$ MAR and no sign of glaucoma, cataract, diabetic retinopathy, or AMD in either eye. Incidence rates were calculated for impairments defined on the basis of uncorrected, best-corrected, and presenting VAs.

The probable cause of visual loss (and, in cases of multiple eye diseases, the major contributor) was indicated on the subject's chart by the field examiner. These indications were subsequently reviewed by a panel of three clinical investigators. The final decisions were based on consensus judgement of the panel members following the examination of all data available for the patient and application of standard clinical criteria. The causes indicated by the field examiner were verified in all cases.

\section{Statistical analysis}

For cumulative incidence rates of the five categories of impairment, 95\% confidence intervals (95\% CI) were calculated using the Poisson distribution for rates of $<5 \%$ and the binomial distribution for those $\geqslant 5 \%$. Correlations between visual impairment and clinical and demographic risk factors were investigated considering each risk factor separately. The factors found to be significant were then included in a stepwise logistic regression model, and regression coefficients (ie, the RRs for the binary variables) were calculated for each after adjustment for the other considered factors. Incidence rates found in this study were compared with those emerging from previous studies (Priverno Eye Study and Beaver Dam Eye Study), and the significance of differences was evaluated with the $\chi^{2}$ test.

\section{Results}

As shown in Table 1, 447 of the 1028 subjects who had been examined in the original 1986-1988 study were ineligible for follow-up (258 had died and 189 were no longer living in Ponza). The remaining 581 all agreed to take part in the second study, but only $411(70.7 \%)$ of these were actually examined. The other 170 (hereafter

Table 1 Follow-up participants in the Ponza Eye Study distributed by sex and age at baseline

\begin{tabular}{|c|c|c|c|c|c|c|c|c|c|c|}
\hline \multirow{2}{*}{$\begin{array}{l}\text { Age (years) } \\
\text { at baseline }\end{array}$} & \multirow{2}{*}{$\begin{array}{l}\text { Examined at } \\
\text { baseline }\end{array}$} & \multirow{2}{*}{$\begin{array}{l}\text { Ineligible for } \\
\text { follow-up }\end{array}$} & \multirow{2}{*}{$\begin{array}{l}\text { Eligible for } \\
\text { follow-up }\end{array}$} & \multicolumn{5}{|c|}{ Nonparticipants in the follow-up } & \multicolumn{2}{|c|}{ Participants in the follow-up } \\
\hline & & & & Refuse & $\begin{array}{l}\text { Health } \\
\text { reasons }\end{array}$ & $\begin{array}{l}\text { Work } \\
\text { reasons }\end{array}$ & $\begin{array}{l}\text { Family } \\
\text { reasons }\end{array}$ & Total & No & $\%$ \\
\hline \multicolumn{11}{|l|}{ Males } \\
\hline 40-49 & 103 & 28 & 75 & 7 & 4 & 10 & 1 & 22 & 53 & 70.7 \\
\hline $50-59$ & 93 & 27 & 66 & 3 & 3 & 2 & 1 & 9 & 57 & 86.4 \\
\hline $60-69$ & 126 & 60 & 66 & 8 & 11 & 1 & 2 & 22 & 44 & 66.7 \\
\hline $70+$ & 123 & 97 & 26 & 6 & 5 & - & 2 & 13 & 13 & 50.0 \\
\hline Total & 445 & 212 & 233 & 24 & 23 & 13 & 6 & 66 & 167 & 71.7 \\
\hline \multicolumn{11}{|l|}{ Females } \\
\hline $40-49$ & 114 & 17 & 97 & 8 & 4 & 3 & 6 & 21 & 76 & 78.4 \\
\hline $50-59$ & 134 & 38 & 96 & 12 & 4 & - & 7 & 23 & 73 & 76.0 \\
\hline $60-69$ & 187 & 74 & 113 & 19 & 12 & - & 6 & 37 & 76 & 67.3 \\
\hline $70+$ & 148 & 106 & 42 & 11 & 9 & - & 3 & 23 & 19 & 45.2 \\
\hline Total & 583 & 235 & 348 & 50 & 29 & 3 & 22 & 104 & 244 & 70.1 \\
\hline \multicolumn{11}{|l|}{ Total } \\
\hline 40-49 & 217 & 45 & 172 & 15 & 8 & 13 & 7 & 43 & 129 & 75.0 \\
\hline $50-59$ & 227 & 65 & 162 & 15 & 7 & 2 & 8 & 32 & 130 & 80.2 \\
\hline 60-69 & 313 & 134 & 179 & 27 & 23 & 1 & 8 & 59 & 120 & 67.0 \\
\hline $70+$ & 271 & 203 & 68 & 17 & 14 & - & 5 & 36 & 32 & 47.1 \\
\hline Total & 1028 & 447 & 581 & 74 & 52 & 16 & 28 & 170 & 411 & 70.7 \\
\hline
\end{tabular}

Male $v s$ female participation in all age groups: $P>0.10$. Total male $v s$ total female $v s$ total male nonparticipation for work reasons $(5.6 v s .0 .9 \%) ; P=0.002$. 
referred to as non-participants) cancelled their appointments without providing any explanation $(n=74$; $43.5 \%)$, or for health reasons $(n=52 ; 30.6 \%)$, job conflicts $(n=16 ; 9.4 \%)$, or family-related problems $(n=28 ; 16.5 \%)$. There was no significant difference between the number of males and the number of females participating in any age group. The mean baseline age of the subjects examined at follow-up was significantly lower than that of the nonparticipants $(55.5 \pm 9.4$ y $v s 59.7 \pm 11.1$ years; $P=0.001$ )

The 12-year cumulative incidence rates for bestcorrected visual loss by age and sex are shown in Table 2 . A total of 50 subjects were defined as incident cases of best-corrected visual loss in the follow-up examination. The overall incidence of binocular blindness was $0.7 \%$ (95\% CI: 0.3-2.2), binocular low- vision 3.9\% (95\% CI: 2.5-6.4), monocular blindness $2.7 \%$ (95\% CI: 1.5-4.9), and monocular low vision 5.0\% (95\% CI: 2.9-7.2). No significant gender-related differences in the incidence figures for any of the age subgroups were revealed although the number of new cases of visual loss was too small to allow us to draw any reliable conclusions in this sense.
Of the general and clinical risk factors considered, age (1.14; 95\% CI: 1.09-1.20), unoperated cataract $(9.29 ; 95 \%$ CI: 1.92-44.9), HIOP (4.45; 95\% CI: 1.27-15.60), and AMD (11.2; 95\% CI: 1.62-76.90) were the only ones that were positively related to incident visual loss, while the association of diabetic retinopathy $(5.08$; $95 \%$ CI: $0.46-$ 56.1) was not significant. None of the other factors (ie, marital status, years of education, occupation, smoking, alcohol intake, cardiovascular diseases, diabetes, hypertension, myopia, glaucoma) had any effect on the risk of visual loss. More than $80 \%$ of incident cases in the year 2000 were subjects over 59 years of age at the baseline exam.

The picture that emerged from our analysis of bestcorrected visual status worsened considerably when we considered the presenting VA of the subjects examined (Table 3). In addition to the 50 subjects who represented incident cases of visual loss even under best-corrected conditions, there were 72 others whose VA would have been normal with optimal optical correction, but for various reasons such correction was not being used. Of these subjects, 35 (49\%) were unaware that they had any correctable form of visual loss. In all cases, this

Table 2 Twelve-year incidence of best-corrected visual loss by age in Ponza Eye Study

\begin{tabular}{|c|c|c|c|c|c|c|}
\hline \multirow[b]{2}{*}{ Age (years) gender } & \multicolumn{3}{|c|}{ Blindness } & \multicolumn{3}{|c|}{ Low vision } \\
\hline & No. of participants at risk & No. & $\%(95 \% C I)$ & No. of participants at risk & No. & $\%(95 \% C I)$ \\
\hline \multicolumn{7}{|l|}{ Binocular } \\
\hline 40-49 & 129 & 1 & $0.8(0.2-4.5)$ & 129 & - & $0.0(0.0-3.1)$ \\
\hline $50-59$ & 130 & - & $0.0(0.0-3.0)$ & 130 & 1 & $0.8(0.1-4.5)$ \\
\hline $60-69$ & 120 & 2 & $1.7(0.5-6.3)$ & 118 & 6 & $5.1(1.1-9.0)$ \\
\hline $70+$ & 32 & - & $0.0(0.0-13.4)$ & 32 & 9 & $28.1(12.5-43.7)$ \\
\hline Total & 411 & 3 & $0.7(0.3-2.2)$ & 409 & 16 & $3.9(2.5-6.4)$ \\
\hline Males & 167 & - & $0.0(0.0-2.4)$ & 167 & 7 & $4.2(2.1-8.8)$ \\
\hline Females & 244 & 3 & $1.2(0.4-3.7)$ & 242 & 9 & $3.7(2.0-7.1)$ \\
\hline \multicolumn{7}{|l|}{ Monocular } \\
\hline $40-49$ & 129 & - & $0.0(0.0-3.1)$ & 128 & 1 & $0.8(0.1-4.6)$ \\
\hline $50-59$ & 129 & 3 & $2.3(0.8-7.0)$ & 129 & 3 & $2.3(0.8-7.0)$ \\
\hline $60-69$ & 117 & 7 & $6.0(1.7-10.3)$ & 112 & 13 & $11.6(5.7-17.5)$ \\
\hline $70+$ & 31 & 1 & $3.2(0.7-20.5)$ & 30 & 3 & $10.0(0.0-20.7)$ \\
\hline Total & 406 & 11 & $2.7(1.5-4.9)$ & 399 & 20 & $5.0(2.9-7.2)$ \\
\hline Males & 166 & 6 & $3.6(1.7-8.0)$ & 164 & 8 & $4.9(2.6-9.8)$ \\
\hline Females & 240 & 5 & $2.1(0.9-4.9)$ & 235 & 12 & $5.1(2.3-7.9)$ \\
\hline
\end{tabular}

Incidence of binocular blindness was defined as development of VA $>1.3 \log$ Mar (or a visual field $<10^{\circ}$ around central fixation) in the better eye in an individual who had best-corrected VA less than or equal to $1.3 \log$ Mar in one or both eyes at baseline. Incidence of binocular low vision was defined as development of VA $>0.5-1.3 \log$ Mar (or a visual field $<20^{\circ}$ around central fixation) in the better eye in an individual who had best-corrected VA less than or equal to $0.5 \log$ Mar in one or both eyes at baseline. Incidence of monocular blindness and monocular low vision was defined by VA in one eye only at follow-up and VA in both eyes at baseline. 
Table 3 The 12-year incidence of visual loss according to best-corrected and presenting VA in the Ponza Eye Study

\begin{tabular}{|c|c|c|c|c|c|}
\hline \multirow[t]{2}{*}{ Visual impairment } & \multirow[t]{2}{*}{ No. of people at risk } & \multicolumn{2}{|c|}{ Best-corrected VA } & \multicolumn{2}{|c|}{ Presenting VA } \\
\hline & & No. & $\%(95 \% C I)$ & No. & $\%(95 \% C I)$ \\
\hline \multicolumn{6}{|l|}{ Binocular } \\
\hline Blindness & 411 & 3 & $0.7(0.3-2.2)$ & 5 & $1.2(0.5-2.9)$ \\
\hline Low Vision & 409 & 16 & $3.9(2.5-6.4)$ & 39 & $9.5(6.7-12.3)$ \\
\hline \multicolumn{6}{|l|}{ Monocular } \\
\hline Blindness & 406 & 11 & $2.7(1.5-4.9)$ & 17 & $4.2(2.7-6.7)$ \\
\hline Low vision & 399 & 20 & $5.0(2.9-7.2)$ & 61 & $15.3(11.8-18.8)$ \\
\hline
\end{tabular}

Best-corrected $v$ s presenting binocular low vision: $P=0.002$. Best-corrected $v$ s presenting monocular low vision: $P=0.0001$.

Table 4 Causes of incident visual loss per person and per eye in the Ponza Eye Study

\begin{tabular}{|c|c|c|c|c|c|c|c|c|c|c|}
\hline & \multicolumn{4}{|c|}{ Causes per person } & \multicolumn{6}{|c|}{ Causes per eye } \\
\hline & \multicolumn{2}{|c|}{ Binocular } & \multicolumn{2}{|c|}{ Monocular } & \multicolumn{2}{|c|}{ Blindness } & \multicolumn{2}{|c|}{ Low vision } & \multicolumn{2}{|c|}{ Total } \\
\hline & No. & $\%$ & No. & $\%$ & No. & $\%$ & No. & $\%$ & No. & $\%$ \\
\hline Cataract & 9 & 47.4 & 15 & 48.4 & 12 & 46.2 & 23 & 53.5 & 35 & 50.7 \\
\hline Glaucoma & 3 & 15.8 & 4 & 12.9 & 2 & 7.7 & 8 & 18.6 & 10 & 14.5 \\
\hline Degenerative myopia & 2 & 10.5 & 1 & 3.2 & 3 & 11.5 & 2 & 4.7 & 5 & 7.2 \\
\hline AMD & 2 & 10.5 & - & - & 2 & 7.7 & 3 & 7.0 & 5 & 7.2 \\
\hline Diabetic retinopathy & - & - & 4 & 12.9 & 3 & 11.5 & 1 & 2.3 & 4 & 5.8 \\
\hline Retinitis pigmentosa & 1 & 5.3 & - & - & 2 & 7.7 & - & - & 2 & 2.9 \\
\hline Retinal detachment & - & - & 2 & 6.5 & 1 & 3.8 & 1 & 2.3 & 2 & 2.9 \\
\hline Trauma & - & - & 2 & 6.5 & 2 & 7.7 & - & - & 2 & 2.9 \\
\hline Advanced central pterygium & - & - & 2 & 6.5 & - & - & 2 & 4.7 & 2 & 2.9 \\
\hline Corneal opacity & - & - & 1 & 3.2 & - & - & 1 & 2.3 & 1 & 1.4 \\
\hline Optic atrophy & - & - & - & - & 1 & 3.8 & - & - & 1 & 1.4 \\
\hline Cataract/AMD & 1 & 5.3 & - & - & - & - & - & - & - & - \\
\hline Cataract/optic atrophy & 1 & 5.3 & - & - & - & - & - & - & - & - \\
\hline Total incidents & 19 & 100.0 & 31 & 100.0 & 26 & 100.0 & 43 & 100.0 & 69 & 100.0 \\
\hline
\end{tabular}

assumption was based on the reportedly normal results of a previous ophthalmological examination. The remaining 37 patients (51\%) were aware that they had visual problems, and corrective lenses had indeed been prescribed. Within this subgroup, $12 / 37$ subjects (32\%) were using the prescribed lenses, but the prescriptions did not provide optimal correction of the current degree of impairment. In many cases, these lenses had been prescribed more than 2 years before our evaluation. The other $25(58 \%)$ were not using the prescribed correction for various reasons: (1) they recognized its inadequacy $(10 / 25 ; 40 \%)$; (2) they felt that it was unnecessary and that their uncorrected VA was sufficient for the activities they were engaged in (32\%); (3) they felt that glasses had a negative impact on their appearance $(16 \%)$; (4) they did not have time to buy the glasses prescribed since there are no optical stores on the island (8\%); and (5) only one subject felt that glasses were too expensive $(4 \%)$. The addition of these 72 subjects to those whose impairment was based on best-corrected VA almost doubled the incidence of presenting binocular blindness (from 0.7 to $1.2 \%$ ) and produced an even more significant increase in the incidence of binocular low vision (from 3.9 to $9.5 \%$ ). There was also an increase in the incidence of monocular blindness (from 2.7 to $4.2 \%$ ) and a three-fold increase in the incidence of monocular low vision (from 5.0 to $15.3 \%$ ).

Table 4 shows the causes of incident visual loss based on best-corrected VAs. The main cause of binocular impairment per person (left side of Table 4) was unoperated cataract $(47.5 \%)$, followed by glaucoma (15.8\%), degenerative myopia (10.5\%), and AMD (10.5\%). Monocular visual loss was caused primarily by unoperated cataracts (48.4\%) followed by glaucoma $(12.9 \%)$ and diabetic retinopathy (12.9\%). When data were analysed according to the number of impaired eyes (right side of Table 4), unoperated cataract (46.2\%) remained the main cause of blindness followed by 
degenerative myopia (11.5\%) and diabetic retinopathy $(11.5 \%)$; cataract was even more important among the causes of low vision per eye (53.5\%), followed by glaucoma (18.6\%) and AMD (7.0\%).

Table 5 shows the results of our analysis of the subgroup considered 'ophthalmologically healthy' at baseline (110 (27\%) of the 411 subjects examined at that time). The percentage of healthy subjects diminished as baseline age increased. Considering uncorrected VAs, we find that 14 (12.8\%) (95\% CI: 6.6-19.0) of these 110 subjects had developed binocular visual loss (uncorrected VA $>0.5 \log$ MAR in the better eye) by the 2000 follow-up, and another 5.5\% (six subjects) had developed monocular impairment. The vast majority of the binocular impairments (12/14) were related to incipient cataracts alone. Of the remaining subjects, one had developed cataract and AMD in both eyes, and the other had bilateral glaucoma. A similar picture emerged for the six cases of monocular impairment: half were caused by incipient cataract, two others had cataract and AMD, and one had glaucoma. The rates of impairment would naturally have been much lower if all 20 of these subjects had been using optimal correction: only one subject ( $0.9 \%$ of the 'healthy-at-baseline' subgroup) (95\% CI: 0.2-5.3) would have had binocular impairment (caused by glaucoma), and three (2.7\%) would have been classified as impaired in one eye (one caused by glaucoma, one by cataract, and one by cataract plus AMD). When presenting VAs were analysed, the incidence rates for binocular and monocular impairments were 3.7\% (95\% CI: 1.5-9.6) and 5.5\% (95\% CI: 1.2-9.7), respectively.

\section{Discussion}

The data collected in this study allowed us to estimate the 12-year incidence of blindness and low vision (as defined by WHO criteria) in an adult free-living (noninstitutionalized persons) population in Italy. It is interesting to note that, compared with the participant group, the 74 subjects who refused to take part in the
2000 follow-up examination included higher percentages of patients who presented at baseline with visual loss (18.9 vs $17.6 \% ; P<0.001)$ and /or untreated cataract (5.6 vs $2.9 \% ; P<0.001)$. On the whole, the nonparticipant subgroup - consisting of 170 persons - had a significantly higher mean age at baseline than the participant group, and this was reflected in the number of subjects who cancelled their appointments due to health problems, in particular those related to mobility, or family problems, which often involved the inability of a relative to accompany the subject to the examination site.

From 1988 to 2000, there was certainly a substantial increase in the overall presence of visual loss, and it is possible that the more recent figures are underestimated to some extent. First of all, at the time of the follow-up study, around one-quarter of the original cohort had died, and of those remaining, 170 refused the follow-up examination. The likelihood of age- and/or diseaserelated visual loss in all of these subjects is fairly high. Compared with the group that was actually examined, the nonparticipant subgroup was significantly older, and $52 / 170(30.6 \%)$ declined to participate in the follow-up study because of 'health problems', which may well have included visual problems. In particular, the prevalence of untreated cataract at baseline among the nonparticipants $(15.6 \%)$, and particularly among those who declined for health reasons $(25.0 \%)$, was significantly higher $(P<0.001)$ than that of the participants $(5.6 \%)$, and this pathology was, in fact, the main cause of incident visual loss in Ponza.

To better understand the visual loss situation in Italy, we compared our 12-year findings for subjects aged 45-69 years at baseline with the 7-year incidence figures from Priverno Eye Study, which was conducted with the same methods and, in part, by the same examiners. ${ }^{7}$ The higher incidence rates for both binocular and monocular blindness and low vision found in the Ponza Study are not significantly different from those found in Priverno (blindness: 0.9 vs $0.2 \%$; low vision: 2.5 vs $1.3 \%$; monocular blindness: 2.9 vs $1.2 \%$; monocular low vision: 5.2 vs $2.9 \%$ ).

Table 5 Twelve-year incidence of bilateral visual loss in healthy subjects at baseline according to uncorrected, best-corrected, and presenting VA at follow-up

\begin{tabular}{|c|c|c|c|c|c|c|c|c|}
\hline & \multirow{2}{*}{$\begin{array}{l}\text { No. examined } \\
\text { at follow-up (a) }\end{array}$} & \multirow{2}{*}{$\begin{array}{l}\text { No. of healthy } \\
\text { subjects at risk } \\
(\% \text { of a })\end{array}$} & \multicolumn{2}{|c|}{ Uncorrected VA } & \multicolumn{2}{|c|}{ Best-corrected VA } & \multicolumn{2}{|c|}{ Presenting VA } \\
\hline & & & No. & $\%$ & No. & $\%$ & No. & $\%$ \\
\hline $40-49$ & 129 & $54(42)$ & 7 & $13.0(4.0-21.9)$ & - & - & 1 & $1.9(0.4-11.2)$ \\
\hline $50-59$ & 130 & $34(26)$ & 3 & $8.8(0.0-18.4)$ & - & - & 1 & $2.9(0.6-18.5)$ \\
\hline $60+$ & 152 & $22(14)$ & 4 & $18.2(2.1-34.3)$ & 1 & $4.5(1.1-30.1)$ & 2 & $9.1(0.0-21.1)$ \\
\hline Total & 411 & $110(27)$ & 14 & $12.7(6.5-19.0)$ & 1 & $0.9(0.2-5.3)$ & 4 & 3.7 (1.5-9.6) \\
\hline
\end{tabular}

Incidence of binocular visual loss was defined as development of uncorrected, best-corrected, and presenting VA $>0.5 \operatorname{logMar}$ in the better eye in an individual who had uncorrected VA equal or better than $0.0 \log$ Mar in both eyes at baseline and absence of the most important eye diseases. 
This observation indicates that the 5-year longer followup had no significant effect on the findings for this age group, probably because the subjects were relatively young at baseline. However, the small size of the sample and/or the small number of incident cases at follow-up may also have played a role.

Untreated age-related cataract appears to be the most important ophthalmological problem in Italy, accounting for over $50 \%$ of incident cases of visual loss per eye in both Italian studies (Ponza: 57.9\%; Priverno 56.4\%). No significant differences were found for other important causes of visual loss, such as diabetic retinopathy, AMD, or corneal pathologies.

To compare the situation in Ponza with that of the United States, we chose the Beaver Dam Eye Study, which had a follow-up interval (10 years) similar to that used in our study. For this purpose, we re-elaborated our data to obtain cumulative incidence figures for the categories of 'monocular changes in vision' and 'changes in vision' used in the US study. 8,9 The comparison was limited to the sub-groups of patients in the two studies who were 43-74 years at baseline.

As Table 6 shows, the incidence figures for monocular changes in vision in subjects of this age group were similar in Beaver Dam and Ponza. However, within the subgroup aged 55-64 year at baseline, there was a significantly higher incidence of 'severe impairment' in Ponza. As far as binocular changes are concerned, Ponza had significantly higher incidence rates for both 'visual impairment' (Ponza 7.0\% vs Beaver Dam 3.7\%, $P=0.004$ ) and 'severe visual impairment' (Ponza $1.4 \%$ vs Beaver Dam $0.4 \%, P=0.031$ ). This difference was largely the result of the much higher rates among the Italian subjects aged 65-74 years at baseline (visual impairment $27 \%$ in Ponza vs $8.9 \%$ in Beaver Dam, and severe visual impairment 7.6 vs $1.2 \%$ in the two communities; both differences are statistically significant at $P<0.001$ ). It seems that, after the age of 64 years, the Ponza population has a higher risk of becoming blind or visually impaired than that of Beaver Dam. The slightly longer follow-up period of our study does not seem sufficient to justify the two-fold difference in incidence for visual impairment and the three-fold difference in incidence for severe impairment.

In epidemiological studies, the incidence of a disease is generally measured in subjects who are healthy at baseline. In contrast, the group 'at risk' for the incidence of visual loss is composed of subjects whose bestcorrected VA at baseline did not exceed the cutoff used to define the disorder, which varies from study to study. ${ }^{7-11}$

Table 6 Incidence ${ }^{\text {a }}$ of monocular changes in vision and changes in vision in Beaver Dam and Ponza Studies among the samples aged 43-74 years at baseline

\begin{tabular}{|c|c|c|c|c|c|c|c|c|c|c|c|c|}
\hline \multirow[b]{3}{*}{$\begin{array}{l}\text { Age group } \\
\text { at baseline }\end{array}$} & \multicolumn{6}{|c|}{ Monocular changes in vision } & \multicolumn{6}{|c|}{ Changes in vision } \\
\hline & \multicolumn{3}{|c|}{ Visual Impairment } & \multicolumn{3}{|c|}{ Severe impairment } & \multicolumn{3}{|c|}{ Visual impairment } & \multicolumn{3}{|c|}{ Severe impairment } \\
\hline & $\begin{array}{l}\text { No. of } \\
\text { participants } \\
\text { at risk }\end{array}$ & $(\%)$ & P-value & $\begin{array}{l}\text { No. of } \\
\text { participants } \\
\text { at risk }\end{array}$ & $(\%)$ & P-value & $\begin{array}{l}\text { No. of } \\
\text { participants } \\
\text { at risk }\end{array}$ & $(\%)$ & P-value & $\begin{array}{l}\text { No. of } \\
\text { participants } \\
\text { at risk }\end{array}$ & $(\%)$ & P-value \\
\hline \multicolumn{13}{|l|}{$43-54$ years } \\
\hline Beaver Dam & 1127 & $(2.1)$ & 0.415 & 1208 & $(0.0)$ & - & 1230 & $(0.7)$ & 0.217 & 1238 & $(0.1)$ & 0.273 \\
\hline Ponza & 138 & (3.6) & & 143 & $(0.0)$ & & 141 & $(2.1)$ & & 143 & $(0.0)$ & \\
\hline \multicolumn{13}{|l|}{ 55-64 years } \\
\hline Beaver Dam & 938 & (10.4) & 0.156 & 991 & (1.2) & 0.022 & 1023 & (2.6) & 0.819 & 1028 & $(0.1)$ & 0.283 \\
\hline Ponza & 142 & $(14.8)$ & & 148 & $(4.1)$ & & 152 & (3.3) & & 154 & $(0.0)$ & \\
\hline \multicolumn{13}{|l|}{$65-74$ years } \\
\hline Beaver Dam & 721 & $(26.1)$ & 0.754 & 868 & (3.5) & 0.253 & 896 & $(8.9)$ & $<0.001$ & 925 & $(1.2)$ & $<0.001$ \\
\hline Ponza & 52 & $(23.1)$ & & 63 & $(0.0)$ & & 63 & $(27.0)$ & & 66 & $(7.6)$ & \\
\hline \multicolumn{13}{|l|}{ Total } \\
\hline Beaver Dam & 2786 & $(11.1)$ & 0.943 & 3067 & (1.4) & 0.831 & 3149 & (3.7) & 0.004 & 3191 & $(0.4)$ & 0.031 \\
\hline Ponza & 332 & (11.4) & & 354 & (1.7) & & 356 & $(7.0)$ & & 363 & (1.4) & \\
\hline
\end{tabular}

a Beaver Dam 10-year incidence, Ponza 12-year incidence.Monocular Changes in Vision: Incidence of monocular visual impairment defined as development of VA of 20/40 or worse in either eye at follow-up in an individual who had better than 20/40 VA in both eyes at baseline. Incidence of monocular severe impairment defined as development of VA of 20/200 or worse in either eye at follow-up in an individual who had better than 20/200 VA in both eyes at baseline.

Changes in Vision: Incidence of visual impairment and severe impairment defined by the better eye.

P-values $=$ Ponza 12-year vs Beaver Dam 10-year. 
The truth is that a variable percentage of these subjects are not actually 'healthy' at baseline because they need a correction to satisfy the definition of persons 'at risk'.

Our study of the Ponza population is the first to consider incident visual loss in subjects defined as 'healthy' based on the uncorrected VAs and absence of eye diseases. This analysis indicates that, over a period of 12 years, a substantial percentage $(18.2 \%)$ of these subjects will have to seek medical care to maintain their normal visual status. Furthermore, the pathologies underlying these impairments are all associated with relatively high treatment costs (eg, cataract surgery) or severe disability (eg, glaucoma, AMD).

In many cases, appropriate corrective lenses would have allowed these patients to achieve normal vision, at least temporarily, but, as our data on presenting VAs show, optimal correction is not always used. When VA was measured under presenting conditions, that is, with the lenses (if any) used by the subject for activities of daily life, 3.7\% of the formerly healthy patients were still classified as bilaterally impaired, and no change was noted in the rate of monocular impairment $(5.5 \%$ based on uncorrected VAs).

The discrepancy between the ideal and real situations that emerges from this analysis has important implications for health-care planning and optimization. It can be attributed to a number of factors, including the accessibility of ophthalmologic and optical services in the community. In our opinion, however, a more important factor is the patients' attitudes towards visual loss and their treatment. Our field experience indicates that many older patients with documented visual loss (women in particular) are unwilling to improve their vision (even with corrective lenses) because they feel that their daily activities do not require better vision or that poor vision is 'a normal part of ageing'. For conditions that require surgical treatment, for example, cataract, which was the cause of over half of all incident cases of visual loss in Ponza, this attitude of neglect is further complicated by the perceived risks and/ or inconvenience associated with surgery and hospitalization. Ophthalmologists can play a fundamental role in correcting this attitude by providing patients with clear information on the risks associated with even minor visual loss, the need for regular follow-up and updating of corrective lenses, and when necessary, discussion of surgical options for the elimination of underlying disease.

\section{References}

1 Thylefors B, Nègrel AD, Pararajasegaram R, Dadzie KY. Available data on blindness (update 1994). Ophthalmic Epidemiol 1995; 2: 5-39.

2 Cerulli L, Cedrone C, Galli MG, Di Marcantonio F. L'Osservatorio oftalmologico di Ponza. Boll Ocul 1988; 67: 467-478.

3 Zapelloni A, Rossi T, Sotis G, Lambiase A, Nucci C, Cedrone $\mathrm{C}$. Indagine preliminare sulla prevalenza delle minorazioni visive e le loro cause a Priverno. Boll Ocul 1993; 72: 993-1002.

4 Ponte F, Giuffrè G, Giammanco R. Prevalence and causes of blindness and low vision in the Casteldaccia Eye Study. Graefes Arch Clin Exp Ophthalmol 1994; 232 469-472.

5 Nicolosi A, Marighi PE, Rizzardi P, Osella A, Miglior S. Prevalence and causes of visual impairment in Italy. Int $J$ Epidemiol 1994; 23: 359-364.

6 Cedrone C, Zapelloni A, Cesareo M, Trematerra M, Corsi A, Cerulli L. Prevalenza delle minorazioni visive e loro cause in popolazioni definite dei comuni di Ponza e Priverno. Minerva Oftalmol 1997; 39: 67-71.

7 Cedrone C, Culasso F, Cesareo M, Nucci C, Palma S, Mancino R et al. Incidence of blindness and low vision in a sample population. The Priverno Eye Study, Italy. Ophthalmology 2003; 110: 548-588.

8 Klein R, Klein BEK, Lee KE. Changes in visual acuity in a population. The Beaver Dam Eye Study. Ophthalmology 1996; 103: 169-177.

9 Klein R, Klein BEK, Lee KE, Cruickshanks KJ, Chappell RJ. Changes in visual acuity in a population over a 10-year period. The Beaver Dam Eye Study. Ophthalmology 2001; 108: 1757-1766.

10 Foran S, Wang JJ, Mitchell P. Causes of incident visual impairment: the Blue Mountains Eye Study. Arch Ophthalmol 2002; 120: 613-619.

11 Foran S, Mitchell P, Wang JJ. Five-year change in visual acuity and incidence of visual impairment. The Blue Mountains Eye Study. Ophthalmology 2003; 110 41-50.

12 Mbulaiteye SM, Reeves BC, Mulwanyi F, Whitworth JA, Johnson G. Incidence of visual loss in rural southwest Uganda. Br J Ophthalmol 2003; 87: 829-833.

13 Cedrone C, Culasso F, Cesareo M, Zapelloni A, Cedrone P, Cerulli L. Prevalence of glaucoma in Ponza, Italy. A comparison with other studies. Opthalmic Epidemiol 1997; 4: 59-72.

14 Ricci F, Cedrone C, Cerulli L. Standardized measurement of visual acuity. Ophthalmic Epidemiol 1998; 5: 41-53.

15 National Academy of Science - National Research Council (NAS - NRC). Recommended standard procedures for the clinical measurement and specification of visual acuity. Report of working group 3. Arch Ophthalmol 1980; 41: 103-148. 